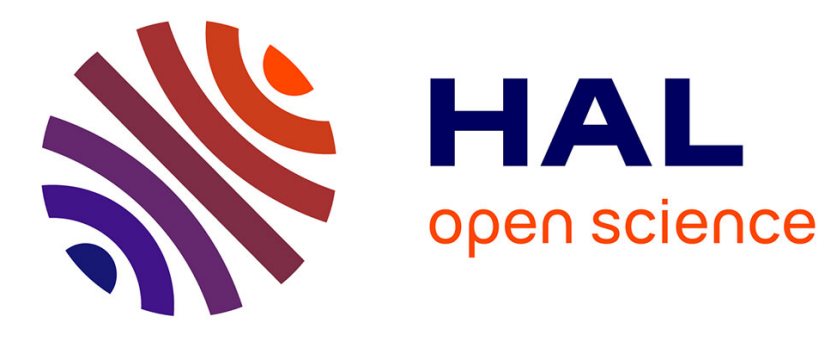

\title{
Impact of priming on global soil carbon stocks
}

Bertrand Guenet, Marta Camino-Serrano, Philippe Ciais, Marwa Tifafi, Fabienne Maignan, Jennifer Soong, Ivan Janssens

\section{To cite this version:}

Bertrand Guenet, Marta Camino-Serrano, Philippe Ciais, Marwa Tifafi, Fabienne Maignan, et al.. Impact of priming on global soil carbon stocks. Global Change Biology, 2018, 24 (5), pp.1873 - 1883. 10.1111/gcb.14069 . hal-01806760

\section{HAL Id: hal-01806760 https://hal.science/hal-01806760}

Submitted on 16 Jun 2021

HAL is a multi-disciplinary open access archive for the deposit and dissemination of scientific research documents, whether they are published or not. The documents may come from teaching and research institutions in France or abroad, or from public or private research centers.
L'archive ouverte pluridisciplinaire HAL, est destinée au dépôt et à la diffusion de documents scientifiques de niveau recherche, publiés ou non, émanant des établissements d'enseignement et de recherche français ou étrangers, des laboratoires publics ou privés. 


\section{Lawrence Berkeley National Laboratory}

\section{Recent Work}

\section{Title}

Impact of priming on global soil carbon stocks.

Permalink

https://escholarship.org/uc/item/9pf2r1kz

Journal

Global change biology, 24(5)

ISSN

1354-1013

\section{Authors}

Guenet, Bertrand

Camino-Serrano, Marta

Ciais, Philippe

et al.

Publication Date

2018-05-01

DOI

10.1111/gcb.14069

Peer reviewed 


\section{Impact of priming on global soil carbon stocks}

Bertrand Guenet ${ }^{1}$, Marta Camino-Serrano ${ }^{2}$, Philippe Ciais ${ }^{1}$, Marwa Tifafi ${ }^{1}$,

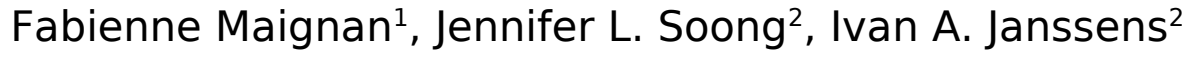

1 Laboratoire des Sciences du Climat et de I'Environnement, LSCE/IPSL, CEACNRSUVSQ, Universite Paris-Saclay, Gif-sur-Yvette, France

2 Department of Biology, Research Group of Plant and Vegetation Ecology, University of Antwerp, Wilrijk, Belgium

Correspondence: Bertrand Guenet, Laboratoire des Sciences du Climat et de I'Environnement, LSCE/IPSL, CEA-CNRS-UVSQ, Universite Paris-Saclay, Gifsur-Yvette, France. Email: bertrand.guenet@Isce.ipsl.fr

Abstract

Fresh carbon input (above and belowground) contributes to soil carbon sequestration, but also accelerates decomposition of soil organic matter through biological priming mechanisms. Currently, poor understanding precludes the incorporation of these priming mechanisms into the global carbon models used for future projections. Here, we show that priming can be incorporated based on a simple equation calibrated from incubation and verified against independent litter manipulation experiments in the global land surface model, ORCHIDEE. When incorporated into ORCHIDEE, priming improved the model's representation of global soil carbon stocks and decreased soil carbon sequestration by $51 \%$ ( $12 \pm 3 \mathrm{Pg} \mathrm{C}$ ) during the period 1901-2010. Future projections with the same model across the range of $\mathrm{CO}_{2}$ and climate changes defined by the IPCC-RCP scenarios reveal that priming buffers the projected changes in soil carbon stocks - both the increases due to enhanced productivity and new input to the soil, and the decreases due to warming-induced accelerated decomposition. Including priming in Earth system models leads to different projections of soil carbon changes, which are challenging to verify at large spatial scales.

\section{KEYWORDS}

carbon cycle, climate change, land surface model, priming, RCP scenario

\section{1 | INTRODUCTION}

Soils hold three times more organic carbon than living biomass (Scharlemann, Tanner, Hiederer, \& Kapos, 2014). At decadal scales, changes in the soil organic carbon reservoir reflect the difference between litter inputs and decomposition by soil micro-organisms, modified by stabilization mechanisms and lateral fluxes such as the export of dissolved organic carbon by runoff or harvest. Even modest changes in either input or 
decomposition processes have the potential to significantly impact soil organic carbon storage, and thus the future dynamics of the coupled carbonclimate system (Jenkinson, Adams, \& Wild, 1991). How soil organic carbon will evolve in response to climate change (affecting both input and decomposition rates) at the global scale is poorly understood, because in the absence of global monitoring of soil organic carbon changes scientists are restricted to using models. In most current soil organic carbon models applied at global scale, the biological and physical mechanisms controlling the stabilization and the decomposition of organic matter are described by first order kinetics equations, which are known to be simplistic (Wutzler \& Reichstein, 2008). For instance, global soil carbon projections are improved when microbial processes are incorporated in comparison to classical first order kinetics (Wieder, Bonan, \& Allison, 2013). As a result, the soil organic carbon models currently included in global Earth system models (ESMs) show limited ability at reproducing the spatial variability in soil organic carbon stocks and exhibit a large spread of future projections (Luo et al., 2016; Todd-Brown et al., 2013). An important group of mechanisms missing in ESMs is the 'priming effect', defined as a modification of soil organic carbon decomposition by the addition of fresh organic carbon, for example, from recent litter input or root exudation of carbohydrates. Although different conditions can lead to priming (Blagodatskaya \& Kuzyakov, 2008), empirical evidence for the significance of priming in enhancing decomposition comes both from laboratory incubations of soil samples after the addition of sugars (Fontaine et al., 2007) and from ecosystem manipulation experiments where the amount of litter is artificially varied and its effect on soil respiration measured (Xiao, Guenet, Zhou, Su, \& Janssens, 2015). In response to climate change and rising atmospheric $\mathrm{CO}_{2}$ concentration, all ESMs project that the primary productivity and thus the litter input to soil organic carbon pools will rise during the next century. Given the current structure of soil organic carbon models in ESMs (Equation 1; see Methods), the increasing primary production results in increasing soil organic carbon, particularly in the modeled soil organic carbon pools with fast and intermediate turnover rates. On the other hand, unless water becomes limiting, soil warming is predicted to accelerate decomposition, reducing this negative feedback and potentially even shifting it to a positive feedback (Nishina et al., 2014). Nevertheless, ESMs generally suggest that soil will be a net sink in the future due to a positive balance between increasing the inputs through primary production increase and increasing the heterotrophic respiration due to temperature increase. Both processes may ultimately mitigate climate change. (Nishina et al., 2014). However, the incorporation of priming into models changes this classical response of soil organic carbon because increases in plant productivity and fresh organic carbon inputs may stimulate decomposition of 
some soil organic carbon (Foereid, Ward, Mahowald, Paterson, \& Lehmann, 2014). Consequently, incorporating the priming mechanism into ESMs may result in very different projections of future soil organic carbon stocks, and thereby of the soil carbon feedback to global warming. In particular, we hypothesize that a representation of priming within an ESM will increase heterotrophic respiration in response to the primary production increase and thereby reduce the soil carbon storage. Consequently, the terrestrial carbon sink predicted by ESMs without priming is overestimated.

\section{2 | MATERIALS AND METHODS}

Here, we start from existing measurements of soil-priming effects on respiration to derive a new formulation (see Equation 2 ) that is incorporated into a process-oriented land carbon-cycle model, known as ORCHIDEE (Guenet, Moyano, Peylin, Ciais, \& Janssens, 2016; Krinner et al., 2005). This model is representative of those used in state-of-the-art ESMs. The goal is to simulate the effects of priming on global and regional historical soil organic carbon dynamics following a perturbation of the carbon cycle from prescribed $\mathrm{CO}_{2}$, land-use and climate change. The equation was firstly proposed as an interesting approach to take into account microbial dynamics in ESMs without adding too much complexity (Guenet Moyano, et al., 2013, 2016; Wutzler \& Reichstein, 2008). The parameters of the equation were established from 20 independent soil incubation experiments with fresh organic carbon additions, representative of different ecosystems and soil types (Guenet et al., 2016). Optimization of parameters was performed using a Bayesian inversion method with priors (Tarantola, 1987) as described by Santaren, Peylin, Viovy, and Ciais (2007) assimilating all data streams in the same cost function. In our case, we used a compilation of priming experiments (Guenet et al., 2016). Then, the models prescribed with optimal parameters were evaluated using an independent dataset of 300 soil incubations (Moyano et al., 2012). This was done for both versions of the model (with or without priming) contributing to an effort to refine parameters values, as previously suggested (Bradford et al., 2016). Although laboratory conditions characterize the response of small soil units where the addition of fresh organic matter is sometimes from added sugars instead of real plant material, this priming equation was also shown to have a good predictive capability at ecosystem-level in reproducing the observed enhancement of soil respiration in ecosystem manipulative experiments for temperate forest when above normal levels of litter were added to the soil (and conversely the respiration decrease when litter was removed) (Guenet et al., 2016). Moreover, it better represents observed soil carbon stocks regional trends compared to the classical approach (Guenet Moyano, et al., 2013). 
ORCHIDEE is a terrestrial ecosystem model that calculates the fluxes of $\mathrm{CO}_{2}$, $\mathrm{H}_{2} \mathrm{O}$, and heat exchanged between the land surface and the atmosphere on a half-hourly basis, and the variations of carbon pools on a daily basis (Krinner et al., 2005). The soil carbon module comes from CENTURY (Parton, Schimel, Cole, \& Ojima, 1987) and describes soil carbon using three pools called active, slow and passive, with different residence times. The dynamics of soil organic carbon (SOC) for each pool is controlled by first order equations:

$$
\frac{\mathrm{dSOC}}{\mathrm{dt}}=I-\mathrm{k} \times \mathrm{SOC} \times \theta \times \tau \times \gamma,
$$

where $I$ is the input of $C$ into each pool and $k$ is the soil organic carbon decomposition rate. $\theta, \tau$, and $\gamma$ are the soil moisture function, the temperature function, and the texture function modulating decomposition, respectively.

In ORCHIDEE-PRIM, we modified Equation (1) to represent the priming effect as:

$$
\frac{\mathrm{dSOC}}{\mathrm{d} t}=I-k \times\left(1-e^{-c \times \mathrm{FOC}}\right) \times \mathrm{SOC} \times \theta \times \tau \times \gamma,
$$

where $c$ is a parameter controlling the interaction of the fresh organic carbon (FOC) pool with the soil organic carbon mineralization. Here, we considered that "fresh organic carbon" represents all the carbon from pools more labile than the pool being affected. This means that for the active carbon pool of the model, fresh organic carbon is the litter (including above and belowground), but for the slow carbon pool fresh organic carbon is the litter plus the active pool, and finally, for the passive carbon pool fresh organic carbon comes from the weighted input that this pools received from litter, active and slow carbon donor pools. The model does not explicitly represent roots exudation but includes this flux into the metabolic belowground litter pool. Furthermore, as fresh organic carbon becomes large, the function (1 $\left.e^{-c \times \text { FOC }}\right)$ approaches unity inducing a saturated effect for high fresh organic carbon inputs as already observed in laboratory (Guenet, Neill, Bardoux, \& Abbadie, 2010) or field experiments (Xiao et al., 2015). Finally, in the ORCHIDEE version used here the soil organic carbon is not discretized with depth whereas soil hydrology and thermal energy are discretized. Therefore, soil temperature and moisture are used to calculate the rates modifiers presented in Equations 2 and 3. Those rates modifiers are the weighted average over the soil profile weighted by the distribution of roots within the profile. 
We ran the two versions of the model (ORCHIDEE and ORCHIDEE-PRIM) at global scale with a $2 \times 2$ degree resolution using historical and future climate and atmospheric $\mathrm{CO}_{2}$ forcing. For the historical period, we used 6hourly climate data to drive the different model versions obtained from the combination of two existing datasets: the Climate Research Unit (CRU) (Mitchell, Carter, Jones, Hulme, \& New, 2004) and the National Centers for Environmental Prediction (NCEP) (Kalnay et al., 1996). To reach equilibrium, we ran ORCHIDEE and ORCHIDEE-PRIM using the first decade of the climate forcing (1901-1910) repeated in a loop, and a pre-industrial value of atmospheric $\mathrm{CO}_{2}$. Once soil organic carbon equilibrium was reached, we performed simulations from 1901 to 2010 driven by climate, land-use change and $\mathrm{CO}_{2}$ data. The prescribed land-use maps are those used in Taylor, Stouffer, and Meehl (2012). For the simulation over the 21st century, we ran the two versions of the model for two different climate and $\mathrm{CO}_{2}$ scenarios (RCP2.6 and RCP8.5) using the bias-corrected outputs produced within the ISI-MIP project (Warszawski et al., 2014). We used the decade between 1951 and 1960 repeatedly to reach equilibrium; we then ran the two versions from 1951 to 2100 using a fixed land use corresponding to the year 1951. We used the climate fields coming from the HadGEM, IPSLCM5A and MIROC-ESM$\mathrm{CH}$ models. To account for the uncertainties in the model parameters, we repeated each simulation (future and historical) varying soil carbon decomposition rate and priming parameter by $\pm 50 \%$. This range of uncertainty corresponds with the average error given by the Bayesian inversion after optimization (Guenet et al., 2016). The values given in the text are the average over the different simulations and are associated with $95 \%$ confidence intervals.

To calculate the turnover of soil organic carbon, we assumed the stocks to be in equilibrium with net primary production (NPP):

$$
\text { residence time }=\frac{S O C}{N P P}
$$

To evaluate the model, we used values of global-scale carbon stocks at $1 \mathrm{~m}$ depth calculated from a meta-analysis (Scharlemann et al., 2014) and we calculated the confidence interval at $95 \%$ from their data. For the latitudinal gradients, we used values coming from the HWSD v1.2, but corrected for the bulk density following a method developed on the version 1.1 (Kochy, Hiederer, \& Freibauer, 2015). NPP values were obtained from the MODIS product. Our residence time estimation using MODIS-NPP is within the range of other datasets used to define the uncertainties (Amundson, 2001; Raich \& Schlesinger, 1992). Since the data used to estimate the residence time are obtained for present day values, we averaged the model outputs for the year 
1990-2010 using simulations done for the historical period with the CRUNCEP forcings.

\section{3 | RESULTS}

Without priming, the modeled global mean soil organic carbon stock amounted to 1,114 Pg C (average over 1991-2010; Figure 1a); the range of uncertainty around this estimate reflecting uncertain turnover rates (see methods) ranges from 650 to $1,570 \mathrm{Pg} \mathrm{C}$. Applying the version of the model with priming (henceforth ORCHIDEEPRIM), we obtained a net higher soil organic carbon stock (mean 1,350 Pg C; range 770-1,930 Pg C) than without priming. When looking at nonboreal regions only, the representation of priming improved the model performance with an increase of the spatial correlation coefficient between observed and modeled soil organic carbon residence time by $7 \%$ (from 0.85 vs. 0.91 in ORCHIDEE-PRIM) and the RMSE values were reduced by $14 \%$ (from 23.5 to 20.2 years in ORCHIDEE-PRIM). This is shown in Figure 1d.

More importantly, the simulations with ORCHIDEE-PRIM better captured the spatial variability of observed soil organic carbon stocks (Figure 1b; Figure 2 ), with a linear regression slope of $0.60 \%$ and $67 \%$ of the observed spatial variance of soil organic carbon explained (Wieder, Boehnert, Bonan, \& Langseth, 2014) when considering all the grid points (Figure 2). In comparison, without priming the slope of the linear regression equaled 0.49 and the same fraction of variance was explained. Moreover, ORCHIDEE-PRIM showed lower root mean square error (RMSE) values than ORCHIDEE (5.9 and $6.2 \mathrm{~kg} \mathrm{C} / \mathrm{m}^{2}$, respectively).

In addition to compare our model results with estimates of global soil organic carbon stocks and their spatial distribution, we also evaluated both the residence time of soil organic carbon (defined here as stock divided by input from net primary production (NPP)) and the change of gross primary production (GPP) (GPP is approximately twice NPP) over time during the historical period. Soil organic carbon residence time derived from observations at global scale (24.4 years on average; Figure 1c) matched that simulated by the model with priming (23.7 years) better than without priming (18.7 years), although both versions of the model produce simulated soil carbon residence time within the range from observations (18.5-32 years) (Amundson, 2001; Raich \& Schlesinger, 1992). This improvement reflects a consistent increase of the residence time with ORCHIDEE-PRIM along the entire latitudinal gradient in all cases (Figure $1 d$ ).

Changes of soil organic carbon simulated by ORCHIDEE and ORCHIDEE-PRIM are already different during the historical period (Figure 3a). Cumulative soil organic carbon storage between 1901 and 2010 was reduced from $25 \pm 8 \mathrm{Pg}$ 
$\mathrm{C}$ in ORCHIDEE to $12 \pm 5 \mathrm{Pg} \mathrm{C}$ in ORCHIDEE-PRIM (Figure 3a). Priming reduced the terrestrial carbon sequestration in particular during the last three decades by $0.26 \pm 0.07 \mathrm{Pg}$ C/year over the 1981-2010 period. With priming, the amount by which primary production increased since the preindustrial period is a critical variable affecting the decomposition of soil organic carbon due to the interaction between fresh organic carbon and soil organic carbon. Our model gives a rate of GPP increase over 1901-2010 of $30 \mathrm{Pg} \mathrm{C} /$ year with an average annual GPP of $133.7 \mathrm{Pg} \mathrm{C}$ for the period 20002010 , which is consistent with a previous estimate of $80 \pm 30 \mathrm{Pg} \mathrm{C}$ for the pre-industrial period (Ciais et al., 2011) and $123 \pm 8 \mathrm{Pg} \mathrm{C}$ for present day (Beer et al., 2010), leading to an increase in annual average GPP of $43 \pm 38$ $\mathrm{Pg} \mathrm{C}$ during the industrial period. Despite a fraction of GPP goes back to the atmosphere through autotrophic respiration and does not enter the soil, we used GPP model outputs compared to existing long-term global estimations (Beer et al., 2010; Ciais et al., 2011) to evaluate the long-term trends of ORCHIDEE.

We then further investigated the effects of priming on future soil organic carbon changes $(\triangle \mathrm{SOC})$ for the two most contrasted climate and $\mathrm{CO}_{2}$ scenarios of the 5th IPCC Assessment Report (RCP2.6 and RCP8.5). For ORCHIDEE and ORCHIDEE-PRIM, $\triangle$ SOC increased by a similar amount until about 2040 in both scenarios. But after that date, when climate and $\mathrm{CO}_{2}$ trajectories begin to diverge more substantially between RCP2.6 and RCP8.5 (Figure 4), the two model versions produced very different soil organic carbon future trajectories (Figure 3). In the RCP8.5 simulation (Figure 3c), a decrease of $\triangle S O C$ was obtained after about 2040, both with and without priming. Yet, the decrease of $\triangle \mathrm{SOC}$ was much smaller when priming was included. In the RCP2.6 scenario, atmospheric $\mathrm{CO}_{2}$ concentration peaks in the 2050s and then slightly decreases, before temperature stabilizes (Figure 4, Meinshausen et al., 2011). Primary production keeps pace with $\mathrm{CO}_{2}$ to reach a peak in the 2050s, after which it slowly decreases until 2100 , but still at a higher level than before 2000. ORCHIDEE predicts significantly lower $\Delta$ SOC when priming is taken into account for RCP2.6, driven by high NPP and inputs to the soil, a response similar to the one of the historical simulation (Figure 3b). 

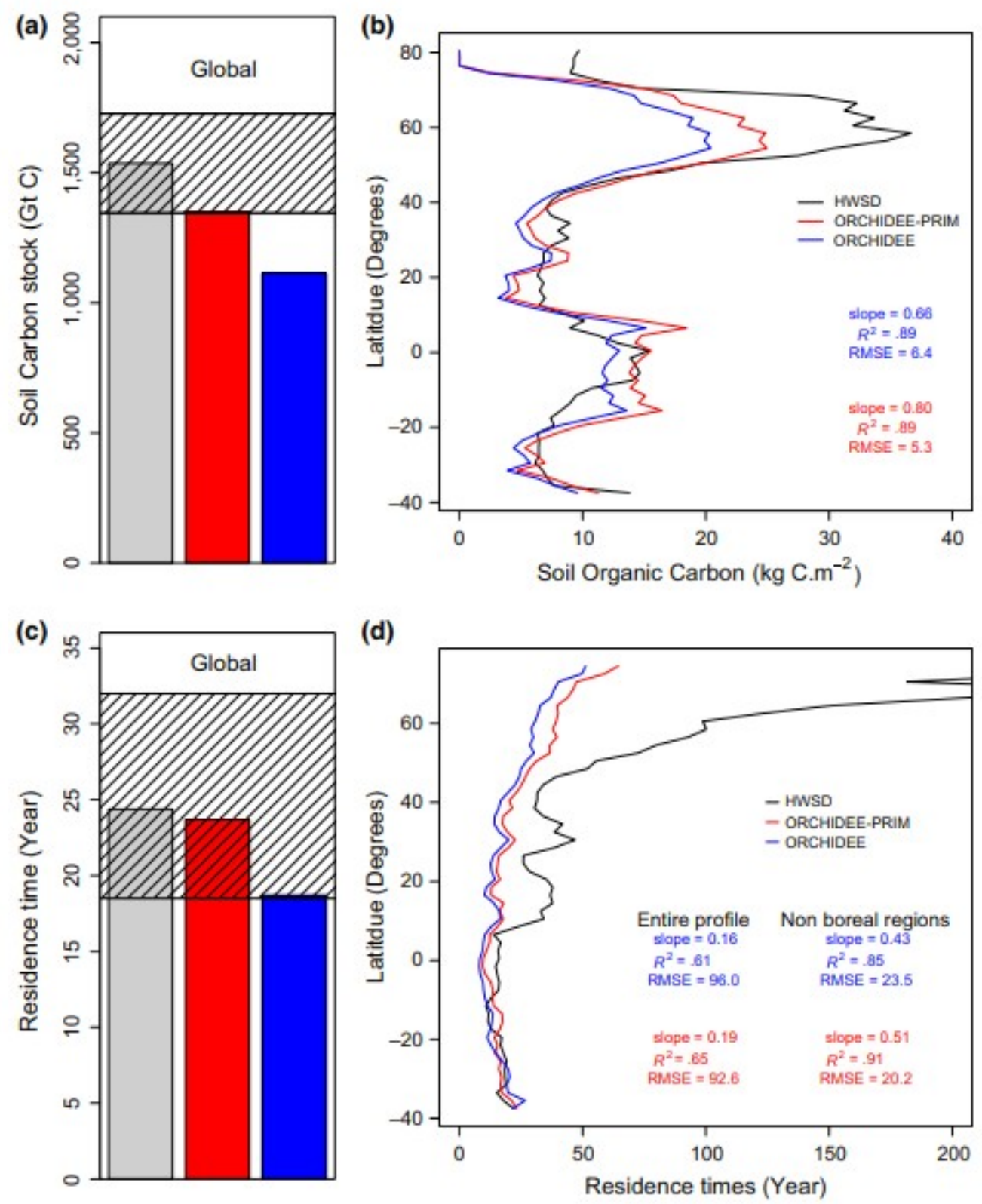

FIGURE 1 (a) Global soil carbon stocks in Pg of carbon. The gray bar indicates the observed stocks, the red bar the stock predicted by ORCHIDEE-PRIM and the blue bar ORCHIDEE. The hatched area is the 95\% confidence interval. (b) Latitudinal profiles of the soil organic carbon stocks predicted by the models (ORCHIDEE-PRIM in red and ORCHIDEE in blue) and the stocks from the HWSD corrected for the bulk density. (c) Global residence times in years. The gray bar indicates the residence time calculated from global data products, the red bar the residence time predicted by ORCHIDEE-PRIM and the blue bar ORCHIDEE. The hatched area represents a range of published values (Amundson, 2001; Raich \& Schlesinger, 1992). (d) Latitudinal profiles of the 
residence times predicted by the models (ORCHIDEE-PRIM in red and ORCHIDEE in blue) and the residence times calculated from global data products

We also found that in all simulations the slope of the relationship between soil organic carbon storage and NPP is positive, but it is always lower in the model version including priming, indicating that a unit change in input causes a smaller SOC accumulation with priming. Nevertheless, the relationship between soil organic carbon storage and NPP was model- and scenario-dependent, with a higher proportion of $\triangle \mathrm{SOC}$ explained by changes in NPP for RCP2.6 than for RCP8.5 (Figure 5). Compared to CMIP5 models, soil organic carbon storage in ORCHIDEE seems to be more controlled by the increase of NPP for RCP2.6 while the variance explained is similar for RCP8.5 (compare Figures 5 and 6). 
(a)

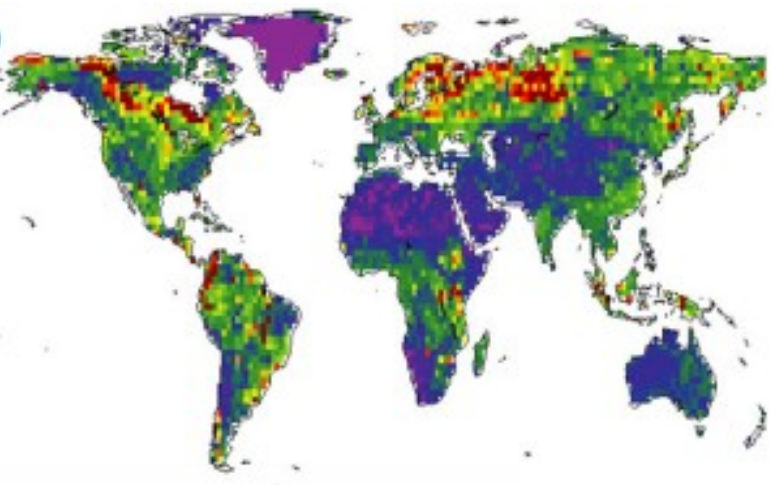

(b)

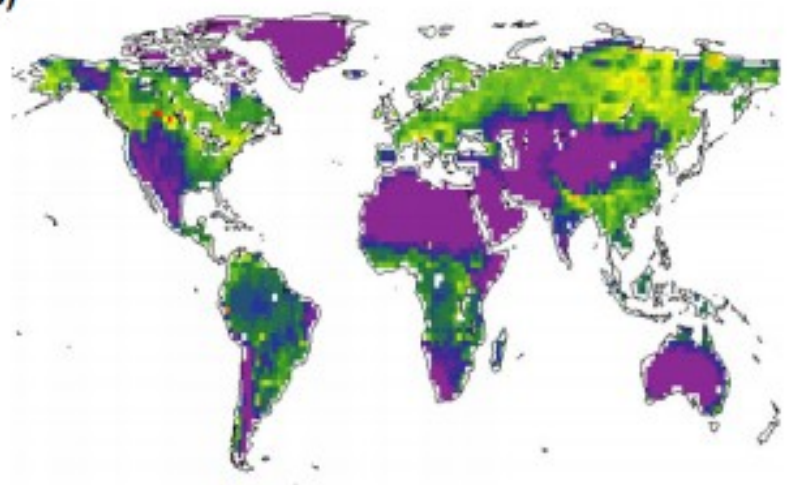

(c)
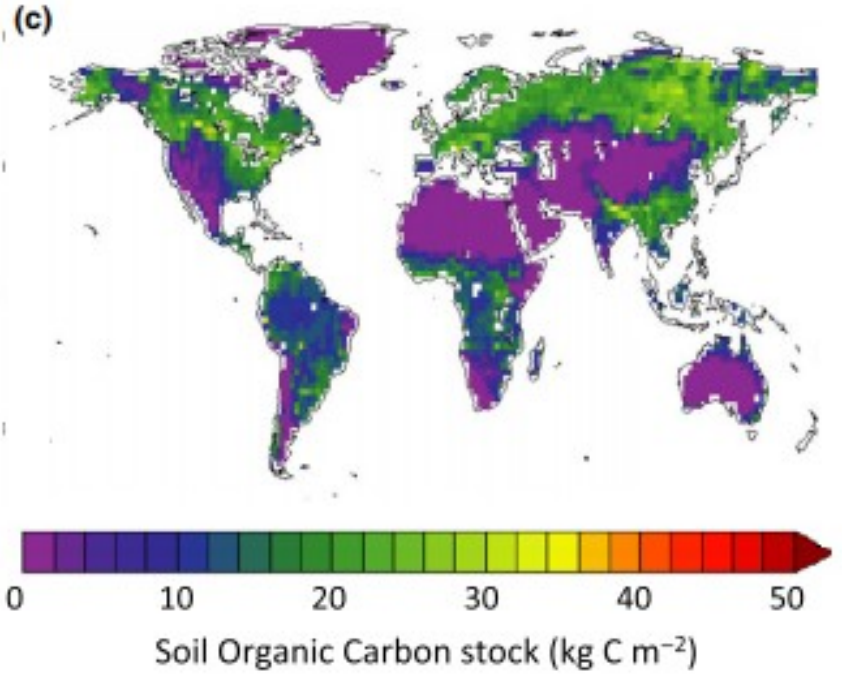

FIGURE 2 Global soil organic carbon content from (a) observations, (b) ORCHIDEE-PRIM $\left(R^{2}=0.67\right.$, slope $\left.=0.6, \mathrm{RMSE}=5.9\right)$ and $(\mathrm{c})$ ORCHIDEE $\left(R^{2}\right.$ $=0.67$, slope $=0.5$, RMSE $=6.2$ )

\section{4 | DISCUSSION}

When priming is included, the model predicts higher soil organic carbon stocks for present day. This is apparently counter-intuitive as priming is conceptually expected to increase soil organic carbon decomposition. This 
result is due to the different parameter values of decomposition rates in ORCHIDEE vs. ORCHIDEE-PRIM. The values used for ORCHIDEE being calibrated from an incubation dataset were priming occurs, they are higher than ORCHIDEE-PRIM even in absence of effects on those rates from changing fresh organic carbon inputs like in ORCHIDEE-PRIM. The low NPP during the first decade of 1901-2010 reduced the decomposition rates in ORCHIDEE-PRIM inducing higher soil organic carbon stocks (Equation 2). The soil organic carbon stock predicted by ORCHIDEE-PRIM is closer to that reported in Scharlemann et al. (2014) based on all the observation-based global soil organic carbon stock estimates (1,540 Pg C, excluding wetlands and old frozen carbon, with 95\% confidence interval 1,350-1,730 Pg C, Figure 1a) compared to ORCHIDEE. Nevertheless, none of both model versions reproduces the high-residence times observed in permafrost soils and wetlands because they lack specific descriptions of reduced decomposition in these two soil types. When the spatial distribution of the soil organic carbon stocks is evaluated (Figure 2), ORCHIDEE-PRIM showed lower root mean square error (RMSE) values than ORCHIDEE (5.9 and $6.2 \mathrm{~kg}$ $\mathrm{C} / \mathrm{m}^{2}$, respectively) comparable with an approach with explicit representation of microbial process (Wieder et al., 2013). Nevertheless, the soil organic carbon stock represented by both models is largely driven by the primary production and the performance of the model might be biased by the ability of the model to represent the carbon inputs though primary production. To evaluate the ability of ESMs to reproduce the soil carbon stocks independently of their performance for primary production, the soil organic carbon residence time is classically used (Koven, Chambers, et al., 2015; Todd-Brown et al., 2013). This is because soil organic carbon residence time, together with NPP almost entirely determines the behavior of soil organic carbon storage in simulations of the perturbed carbon cycle. Differences in soil organic carbon residence time in other ESMs have been found to explain most of the differences in simulated soil organic carbon change (Todd-Brown et al., 2013).

In addition to differences for the present-day period, the dynamics of soil organic carbon stocks simulated by ORCHIDEE and ORCHIDEE-PRIM are already different during the historical period (Figure $3 a$ ). In this period, primary production increased due to rising $\mathrm{CO}_{2}$ and warming-induced lengthening of the growing season in the Northern Hemisphere (Long, Ainsworth, Rogers, \& Ort, 2004). Increasing primary production enhanced the inputs of labile carbon into soils, which accelerated the decomposition of intermediate and even passive carbon pools when priming was included in accordance with previous observations (Fontaine et al., 2007; Guenet, Juarez, Bardoux, Luc, \& Claire, 2012). For future climate simulations, both scenarios induced different dynamics. In the RCP8.5 simulation, soil organic 
carbon stocks decreased after about 2040, both with and without priming; this is due to the fact that for high warming, warming-increased decomposition exceeds increased carbon input causing a decrease in carbon stocks - even without priming - as in other ESMs (Nishina et al., 2014). Interestingly, the decrease of $\triangle \mathrm{SOC}$ was much smaller when priming was included. This behavior can be explained by the saturation of the priming effect in Equation 2. Priming is represented using a fresh organic carbondependent function ( $\left.1-e^{-c \times F O C}\right)$, as fresh organic carbon continues to increase globally in the future, this function approaches unity and the decomposition of soil organic carbon is no longer accelerated by more fresh organic carbon input. This saturation of the effects of priming is consistent with previous litter manipulations experiments in a Chinese grassland (Xiao et al., 2015). Thus, despite increasing fresh organic carbon addition to the soil from net primary production (Figure 7 ), the decomposition rates $(k)$ of soil carbon pools become comparable to the decomposition rates derived from first order kinetics assumptions. Consequently, the further decrease in $\triangle \mathrm{SOC}$ is attenuated. For RCP 2.6 scenario, the soil carbon stocks increase with or without priming but when priming is considered, the $\triangle \mathrm{SOC}$ is reduced. This difference in this scenario is explained by a continued decline of soil organic carbon sequestration during the simulated period (1950-2100) mainly driven by the dynamics of inputs from net primary production. In the RCP2.6 scenario, the fresh organic carbon inputs to the soil increase until 2040 and then stabilize but remain high compared to the 20th century (Figure 7) but not high enough for the priming effect to saturate like in the RCP8.5 simulation. Thus, priming effect is maintained at a high level reducing the soil organic carbon sequestration for the RCP2. 6 scenario compared to the model without priming (Figure 3c), which stores a higher proportion of NPP in the soil pools (Figure 5).

Knowing that $\triangle \mathrm{NPP}$ is a major driver for $\triangle \mathrm{SOC}$, we analyzed the relationship between both variables. For both model and whatever the scenario, the slope of the relationship between soil organic carbon storage and NPP is positive. Nevertheless, it is always lower in the model version including priming, suggesting that, as NPP increases, a smaller proportion of it is stored in the soil when priming effects are considered, and the opposite, when NPP decreases soil organic carbon losses remain higher. The relationship between soil organic carbon storage and NPP was model- and scenario-dependent, with a higher proportion of the variation in soil organic carbon storage explained by the changes in NPP for RCP2.6 than for RCP8.5 (Figure 5). Nevertheless, compared to CMIP5 models, soil organic carbon storage in ORCHIDEE seems more controlled by NPP increase for RCP2.6 while the variance explained is similar for RCP8.5 (Figure 6). Furthermore, the model future prediction does not take into account the effect of wetlands 
and permafrost on the future land to atmosphere $\mathrm{CO}_{2}$ fluxes. These fluxes may represent an important feedback on climate (Hollesen, Matthiesen, Møller, \& Elberling, 2015; Richey, Melack, Aufdenkampe, Ballester, \& Hess, 2002) but are still not well represented in ESMs (Koven, Lawrence, \& Riley, 2015). Therefore, our analysis should be more considered as a sensitivity analysis of the incorporation of priming into a state-of-the-art land surface component of an ESM than an estimation of priming intensity at global scale.
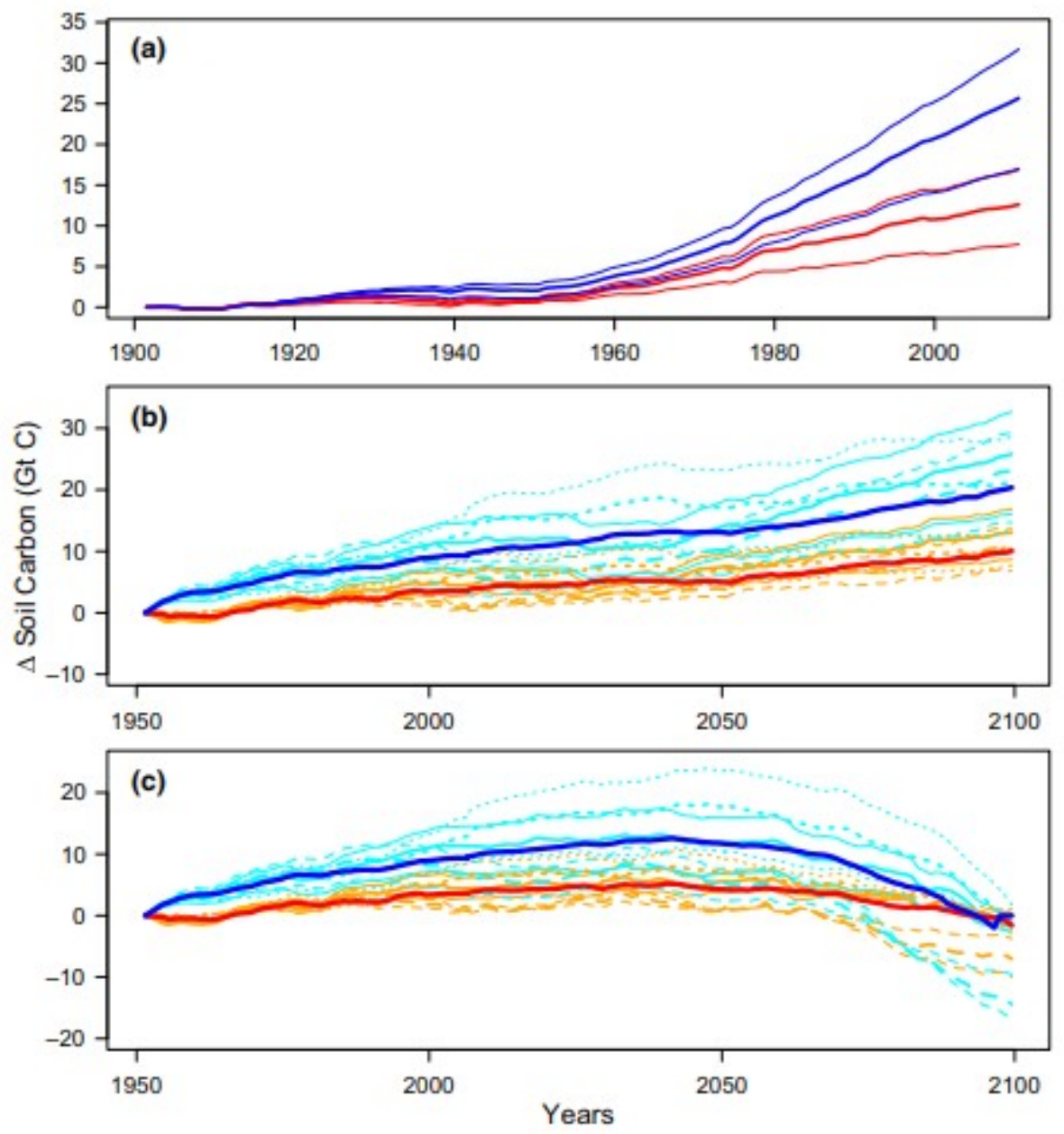

FIGURE 3 Evolution of the soil carbon stock change from: (a) 1901 to 2010. (b) from 1951 to 2100 for the RCP2.6. (c) from 1951 to 2100 for the RCP8.5. In all figures, red indicates the values predicted by ORCHIDEE-PRIM and blue by ORCHIDEE. For all figures, the thin lines are the simulations with the parameter values modified by $50 \%$. For (b) and (c), the light blue and the orange lines represent the simulations performed with the climate forcings from the HadGEM, IPSL-CM5A and MIROC-ESM-CH models for ORCHIDEE and ORCHIDEE-PRIM, respectively 

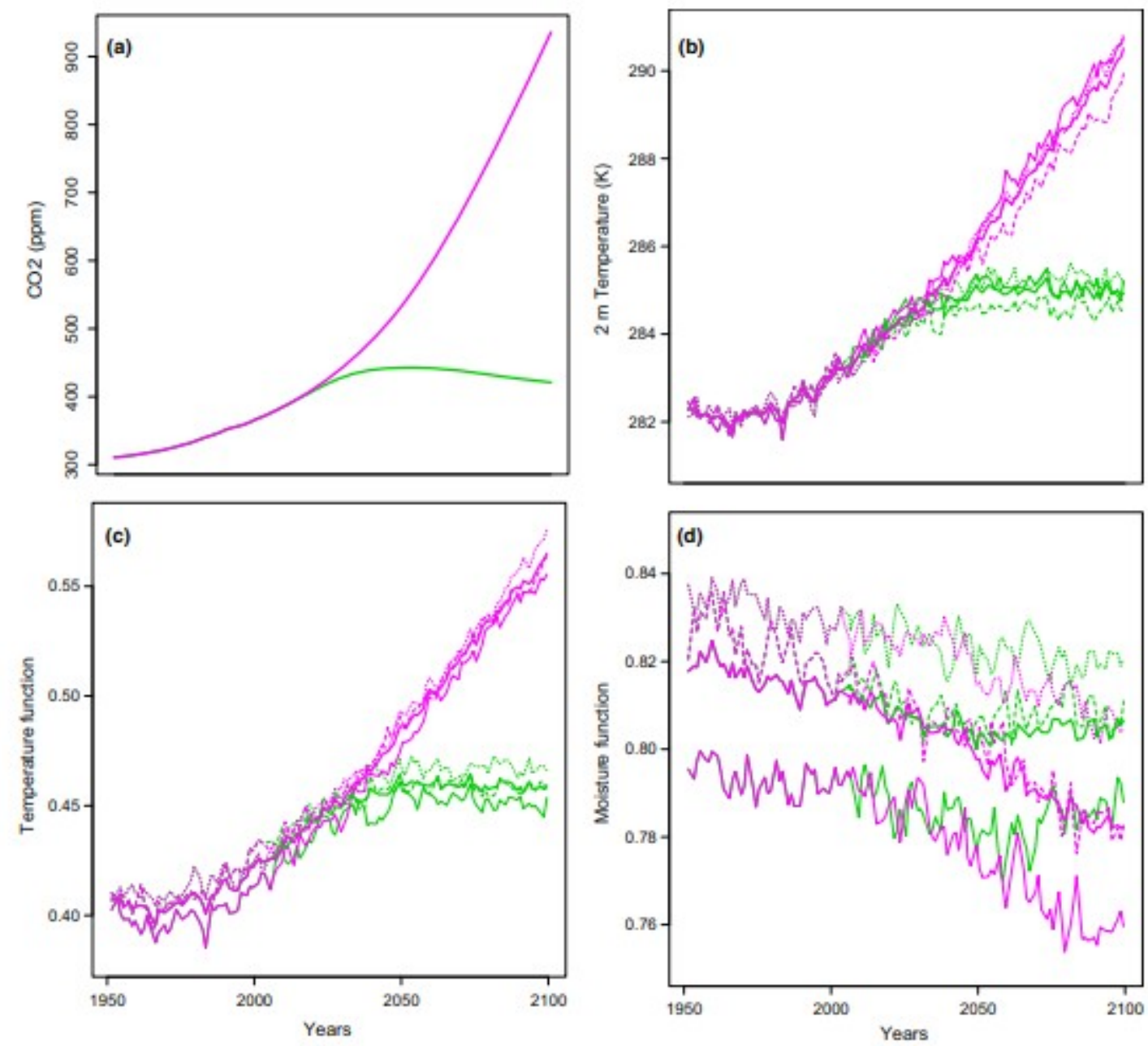

FIGURE 4 Evolution of the (a) atmospheric $\mathrm{CO}_{2}$ concentration (ppm), (b) temperature at $2 \mathrm{~m} \mathrm{(K)}$, (c) temperature function modulating the decomposition rate and (d) soil moisture function modulating the decomposition rate for the RCP2.6 scenario (green) and the RCP8.5 one (pink). Bold lines are the average of the three ESMs outputs used. Prescribed atmospheric $\mathrm{CO}_{2}$ is the same for all the simulations

Field manipulation and laboratory experiments consistently suggest that priming is a major mechanism affecting soil carbon cycling (Blagodatskaya \& Kuzyakov, 2008; Chen et al., 2014; Fontaine et al., 2007; van Groenigen, Qi, Osenberg, Luo, \& Hungate, 2014; Xiao et al., 2015), yet the process is still not represented in land surface models. Here, we included a simple representation of the priming effect in the ORCHIDEE model calibrated from laboratory incubation data and verified by data from litter manipulation experiments (Guenet et al., 2016). This approach has already proven successful in representing long-term trends of soil organic carbon stocks observed at regional scales (Guenet Moyano, et al., 2013) and long-term experiments results compared to classical first order kinetics (Guenet, Eglin, 
et al., 2013). Priming is generally defined as a modification of the decomposition rates of the soil organic matter (so-called stable pools) induced by the addition of fresh organic matter (from the labile pools) (Kuzyakov, Friedel, \& Stahr, 2000). To our knowledge, all the theoretical schemes proposed to explain priming have used this two pools approach (Blagodatskaya \& Kuzyakov, 2008; Chen et al., 2014; Fontaine, Mariotti, \& Abbadie, 2003; Guenet, Danger, Abbadie, \& Lacroix, 2010) and here we generalized it to a model with more than two pools assuming that any stable soil organic matter pool can be primed if labile material is available. This is in accordance with previous experimental results showing that old soil organic matter can be rapidly primed when fresh organic carbon is added (Fontaine et al., 2007; Guenet et al., 2012). The results from simulations presented here suggest that the ORCHIDEE-PRIM model performance is also improved at global scales compared to ORCHIDEE. Based on our previous work (Guenet et al., 2016), we estimated the uncertainty of the soil organic carbon dynamics due to parameter optimization procedures by repeating each simulation (future and historical) and modifying the decomposition module parameters by $\pm 50 \%$ (the average error on each parameter). We observed that despite the modifications of parameter values the behavior of the model did not change drastically, giving confidence to the results presented in this study. A modification of the decomposition equation to represent priming effects improved the model's capacity to reproduce the observed spatial variance of soil organic carbon and changed the projections of future soil organic carbon dynamics in response to climate and $\mathrm{CO}_{2}$ changes. Compared to previous attempts to improve soil organic carbon dynamics in land surface models using Michaelis-Menten or explicit microbial biomass (Sulman, Phillips, Oishi, Shevliakova, \& Pacala, 2014; Tang \& Riley, 2014; Wieder et al., 2013, 2015), this simple approach does not need to drastically change the structure of the model and the model performances are rather similar. It is challenging to develop simple and robust equations that are easily adaptable to land surface models (i.e., with few parameters, not sitedependent, etc.). Yet the priming equation we propose partly overcomes this limit in complexity by the use of a single priming parameter obtained from an empirical formulation tested against a robust set of incubation and field experiments (4). However, the equation does not yet account for the modulation of priming intensity by nutrient availability, particularly by mineral nitrogen (Chen et al., 2014). When fresh organic carbon inputs increase, nutrient demands by micro-organisms increase as well, and to satisfy this demand, soil organic carbon mineralization typically increases, inducing $\mathrm{CO}_{2}$ emissions and nutrient release. Nutrient mining is considered to be one of the mechanisms underlying priming (Chen et al., 2014), and therefore relating priming parameters to nutrient availability might be a next 
step in improving the representation of priming in land surface models. This was already done at local scale by Perveen et al. (2014) who showed the importance of feedbacks between plant growth and soil organic mineralization to explain priming intensity. Furthermore, including microbial processes occurring at fine scales in large-scale models used for long-term predictions may imply to also take into account Darwinian evolution that may impact interactions between plant and soil microorganisms quite substantially (Barot, Loeuille, Perveen, Shahzad, \& Fontaine, 2014). Indeed, micro-organism lifetime is short and Darwinian evolution may affect microorganisms characteristics rapidly in response to environmental changes (Velicer \& Lenski, 1999). Different approaches have been proposed for ocean that might be useful for soils too (Follows, Dutkiewicz, Grant, \& Chisholm, 2007). Nevertheless, we have shown that the loss of soil organic carbon sequestration due to priming is quite substantial and strongly buffers the feedback of soil organic carbon sequestration on climate change. We argue that priming must be incorporated into the next generation of ESMs to make more realistic projections of soil carbon changes.

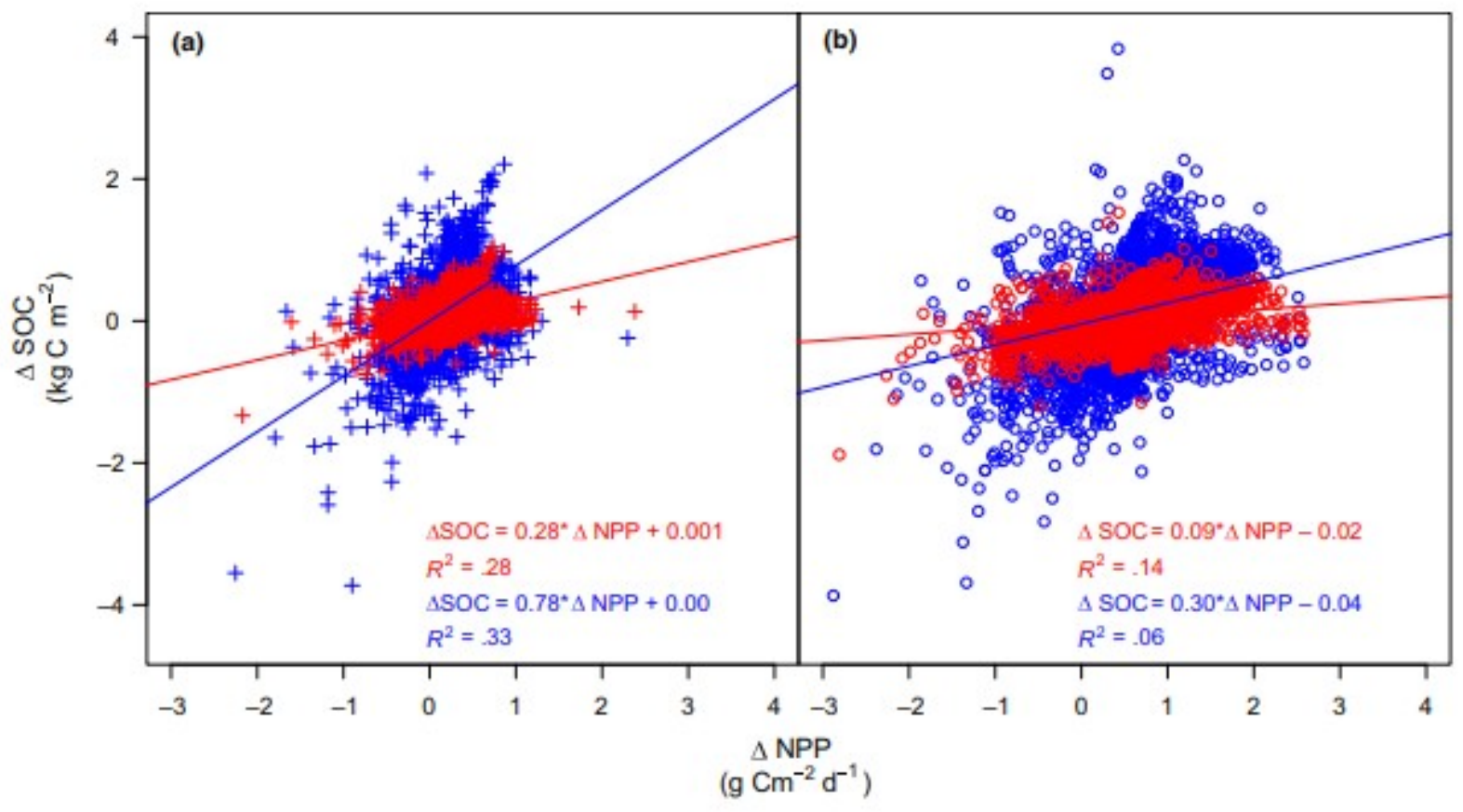

FIGURE 5 Soil organic carbon storage change $(\triangle \mathrm{SOC})$ against NPP change between 1950 and 2100. (a) for the RCP2.6 scenario and (b) RCP8.5 scenario. Results from ORCHIDEE are in blue and ORCHIDEE-PRIM in red. Each point represents a grid cell 


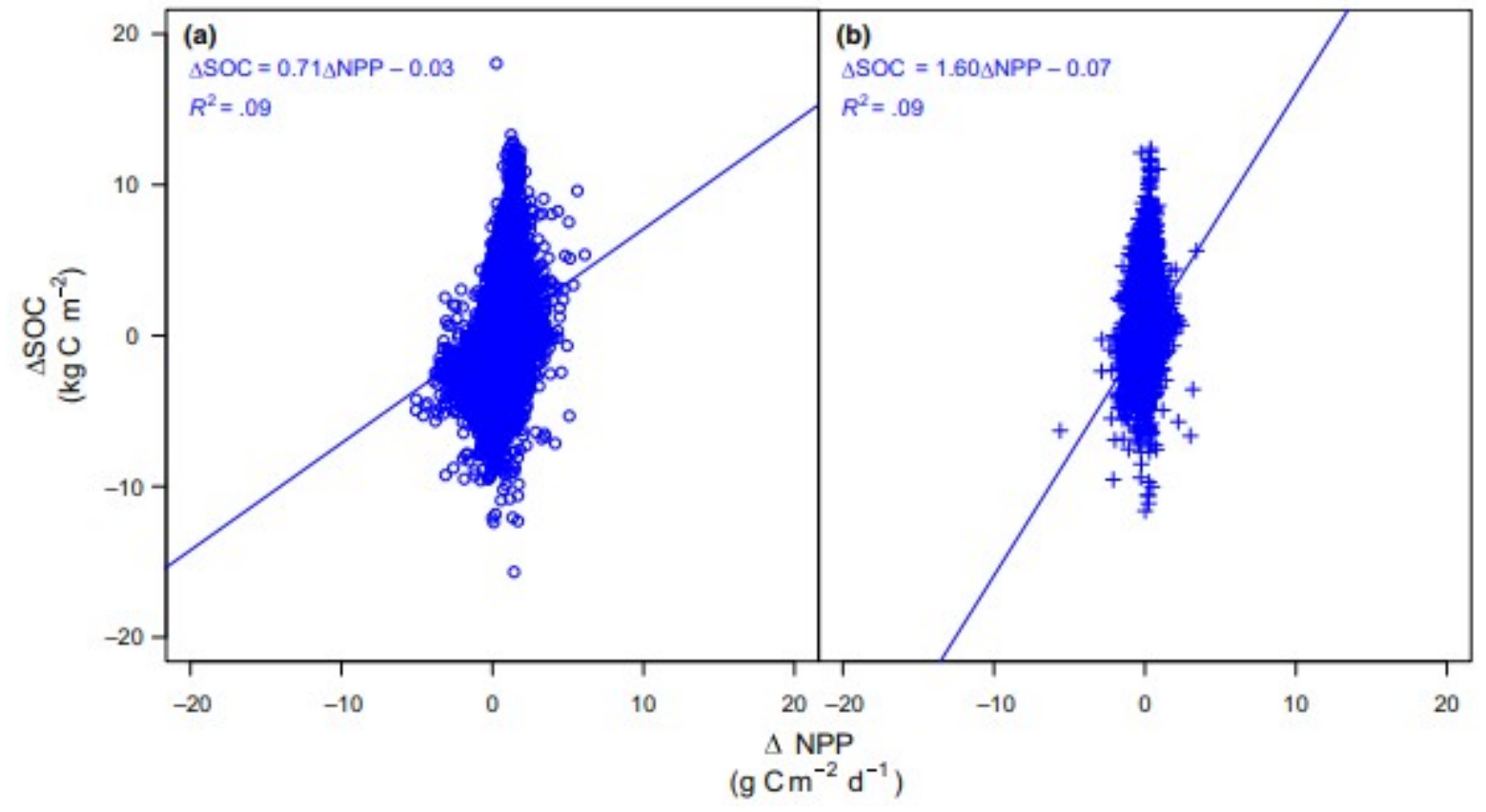

FIGURE 6 Plot between soil organic carbon $(\triangle \mathrm{SOC})$ storage and the net primary production differences ( $\triangle \mathrm{NPP}$ ) during the simulation for different ESMs (bcc-csm1-1, BNU-ESM, CanESM2, CCSM4, CESM1-CAM5, GFDL-ESM2G, IPSL-CM5A-LR, MIROC-ESM, HadGEM2-ES, MPIESM-LR, NorESM1-M) for RCP 2.6 (a) and RCP 8.5 (b). Each point represents a grid cell and all ESMs have been grouped together 


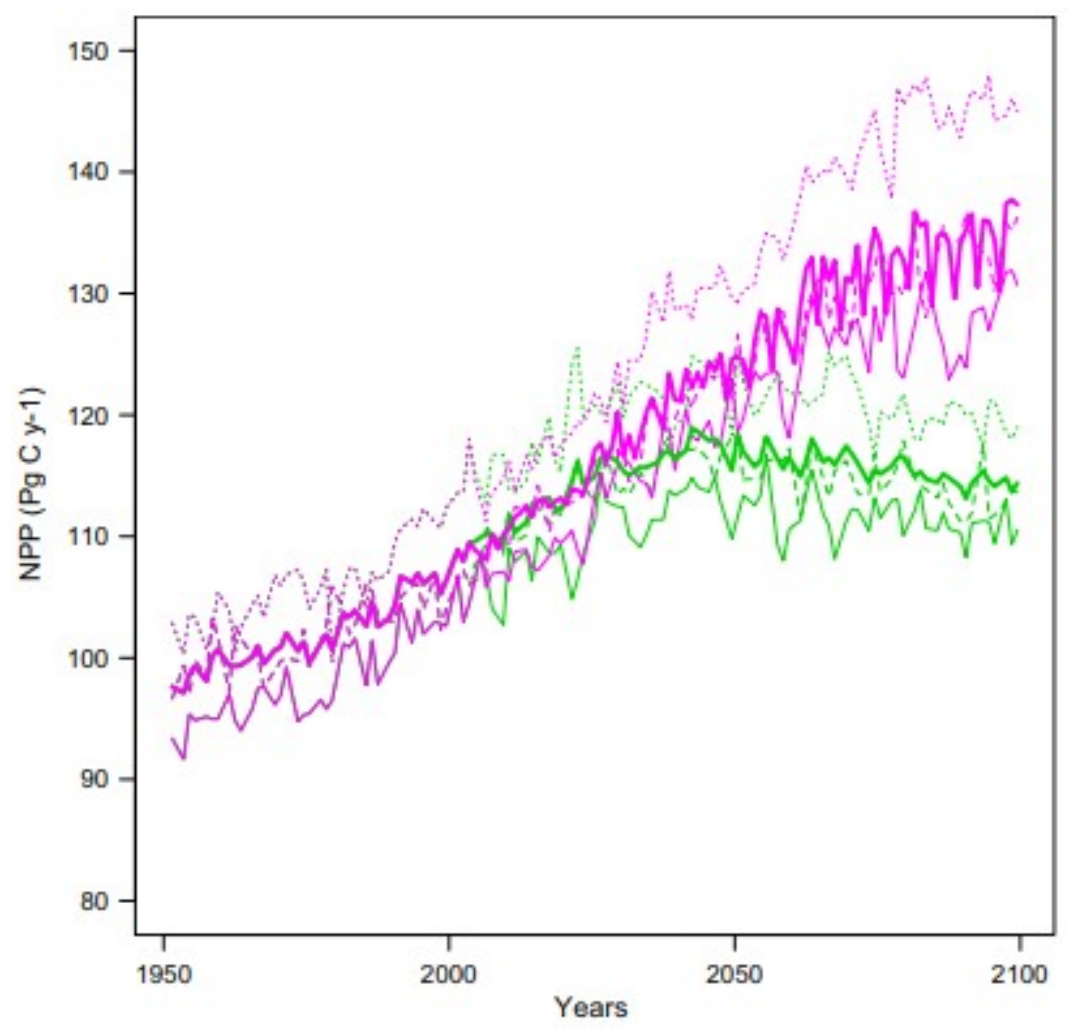

FIGURE 7 Evolution of simulated global NPP (Pg C/year) modulating the decomposition rate through priming effects in the RCP2.6 scenario (green) and the RCP8.5 (pink). Bold lines are the average of NPP simulated using climate from three ESMs

\section{ACKNOWLEDGEMENTS}

The MODIS-NPP data product was obtained through the online Data Pool at the NASA Land Processes Distributed Active Archive Center (LP DAAC), USGS/Earth Resources Observation and Science (EROS) Center, Sioux Falls, South Dakota (https://lpdaac.usgs.gov/da ta_access).

\section{REFERENCES}

Amundson, R. (2001). The carbon budget in soils. Annual Review of Earth and Planetary Sciences, 21, 535-562. https://doi.org/10.1146/annure v.earth.29.1.535

Barot, S., Loeuille, N., Perveen, N., Shahzad, T., \& Fontaine, S. (2014). Nutrient enrichment and local competition influence the evolution of plant mineralization strategy : A modelling approach. Journal of Ecology, 102, 357366. https://doi.org/10.1111/1365-2745.12200

Beer, C., Reichstein, M., Tomelleri, E., Ciais, P., Jung, M., Carvalhais, N., ... Bondeau, A. (2010). Terrestrial gross carbon dioxide uptake: Global 
distribution and covariation with climate. Science, 329, 834-838. https://doi.org/10.1126/science.1184984

Blagodatskaya, E., \& Kuzyakov, Y. (2008). Mechanisms of real and apparent priming effects and their dependence on soil microbial biomass and community structure: Critical review. Biology and Fertility of Soils, 45, 115131. https://doi.org/10.1007/s00374-008-0334-y

Bradford, M. A., Wieder, W. R., Bonan, G. B., Fierer, N., Raymond, P. A., \& Crowther, T. W. (2016). Managing uncertainty in soil carbon feedbacks to climate change. Nature Climate Change, 6, 751-758. https://doi.org/10.1038/nclimate3071

Chen, R., Senbayram, M., Blagodatsky, S., Myachina, O., Dittert, K., Lin, X., ... Kuzyakov, Y. (2014). Soil C and $\mathrm{N}$ availability determine the priming effect: Microbial $\mathrm{N}$ mining and stoichiometric decomposition theories. Global Change Biology, 20, 2356-2367.

Ciais, P., Tagliabue, A., Cuntz, M., Bopp, L., Scholze, M., Hoffmann, G., ... Koven, C. (2011). Large inert carbon pool in the terrestrial biosphere during the Last Glacial Maximum. Nature Geoscience, 5, 74-79.

Foereid, B., Ward, D. S., Mahowald, N., Paterson, E., \& Lehmann, J. (2014). The sensitivity of carbon turnover in the Community Land Model to modified assumptions about soil processes. Earth System Dynamics, 5, 211-221. https://doi.org/10.5194/esd-5-211-2014

Follows, M. J., Dutkiewicz, S., Grant, S., \& Chisholm, S. W. (2007). Emergent biogeography of microbial communities in a model ocean. Science (New York, N.Y.), 315, 1843-1846. https://doi.org/10.1126/sc ience.1138544

Fontaine, S., Barot, S., Barre, P., Bdioui, N., Mary, B., \& Rumpel, C. (2007). Stability of organic carbon in deep soil layers controlled by fresh carbon supply. Nature, 450, 277-280. https://doi.org/10. 1038/nature06275

Fontaine, S., Mariotti, A., \& Abbadie, L. (2003). The priming effect of organic matter: A question of microbial competition? Soil Biology and Biochemistry, 35, 837-843. https://doi.org/10.1016/S0038-0717(03) 00123-8

van Groenigen, K. J., Qi, X., Osenberg, C. W., Luo, Y., \& Hungate, B. A. (2014). Faster decomposition under increased atmospheric $\mathrm{CO}_{2}$ limits soil carbon storage. Science, 344, 508-509. https://doi.org/10. 1126/science.1249534

Guenet, B., Danger, M., Abbadie, L., \& Lacroix, G. (2010). Priming effect: Bridging the gap between terrestrial and aquatic ecology. Ecology, 91, 28502861. https://doi.org/10.1890/09-1968.1 
Guenet, B., Eglin, T., Vasilyeva, N., Peylin, P., Ciais, P., \& Chenu, C. (2013). The relative importance of decomposition and transport mechanisms in accounting for soil organic carbon profiles. Biogeosciences, 10, 2379-2392. https://doi.org/10.5194/bg-10-2379-2013

Guenet, B., Juarez, S., Bardoux, G., Luc, A., \& Claire, C. (2012). Evidence that stable $C$ is as vulnerable to priming effect as is more labile $C$ in soil. Soil Biology and Biochemistry, 52, 43-48. https://doi.org/10. 1016/j.soilbio.2012.04.001

Guenet, B., Moyano, F. E., Peylin, P., Ciais, P., \& Janssens, I. A. (2016). Towards a representation of priming on soil carbon decomposition in the global land biosphere model ORCHIDEE (version 1.9.5.2). Geoscientific Model Development, 9, 841-855. https://doi.org/10.5194/gmd9-841-2016

Guenet, B., Moyano, F. E., Vuichard, N., Kirk, G. J. D., Bellamy, P. H., Zaehle, S., \& Ciais, P. (2013). Can we model observed soil carbon changes from a dense inventory? A case study over England and Wales using three versions of the ORCHIDEE ecosystem model (AR5, AR5-PRIM and O-CN). Geoscientific Model Development, 6, 2153-2163. https://doi.org/10.5194/gmd-6-21532013

Guenet, B., Neill, C., Bardoux, G., \& Abbadie, L. (2010). Is there a linear relationship between priming effect intensity and the amount of organic matter input? Applied Soil Ecology, 46, 436-442. https://doi. org/10.1016/j.apsoil.2010.09.006

Hollesen, J., Matthiesen, H., Møller, A. B., \& Elberling, B. (2015). Permafrost thawing in organic Arctic soils accelerated by ground heat production. Nature Climate Change, 5, 574-578. https://doi.org/10. 1038/nclimate2590

Jenkinson, D. S., Adams, D. E., \& Wild, A. (1991). Model estimates of $\mathrm{CO}_{2}$ emissions from soil in response to global warming. Nature, 351, 304-306. https://doi.org/10.1038/351304a0

Kalnay, E., Kanamitsu, M., Kistler, R., Collins, W., Deaven, D., Gandin, L., ... Zhu, Y. (1996). The NCEP/NCAR 40-year reanalysis project. Bulletin of the American Meteorological Society, 77, 437-471.

Kochy, M., Hiederer, R., \& Freibauer, A. (2015). Global distribution of soil organic carbon - Part 1: Masses and frequency distributions of SOC stocks for the tropics, permafrost regions, wetlands, and the world. Soil, 1, 351-365. https://doi.org/10.5194/soil-1-351-2015

Koven, C. D., Chambers, J. Q., Georgiou, K., Knox, R., Negron-Juarez, R., Riley, W. J., ... Jones, C. D. (2015). Controls on terrestrial carbon feedbacks by 
productivity versus turnover in the CMIP5 Earth System Models. Biogeosciences, 12, 5211-5228.

Koven, C. D., Lawrence, D. M., \& Riley, W. J. (2015). Permafrost carbon climate feedback is sensitive to deep soil carbon decomposability but not deep soil nitrogen dynamics. Proceedings of the National Academy of Sciences, 112, 201415123. https://doi.org/10.1073/pnas. 1415123112

Krinner, G., Viovy, N., de Noblet-Ducoudre, N., Ogee, J., Polcher, J., Friedlingstein, P., ... Prentice, I. C. (2005). A dynamic global vegetation model for studies of the coupled atmosphere-biosphere system. Global Biogeochemical Cycles, 19, GB1015.

Kuzyakov, Y., Friedel, J., \& Stahr, K. (2000). Review of mechanisms and quantification of priming effects. Soil Biology and Biochemistry, 32, 14851498. https://doi.org/10.1016/S0038-0717(00)00084-5

Long, S. P., Ainsworth, E. A., Rogers, A., \& Ort, D. R. (2004). Rising atmospheric carbon dioxide: Plants FACE the future. Annual Review of Plant Biology, 55, 591-628. https://doi.org/10.1146/annurev.arplant. 55.031903 .141610

Luo, Y., Ahlstrom, A., Allison, S. D., Batjes, N. H., Brovkin, V., Carvalhais, N., ... Georgiou, K. (2016). Toward more realistic projections of soil carbon dynamics by Earth system models. Global Biogeochemical Cycles, 30, 40-56.

Meinshausen, M., Smith, S. J., Calvin, K., Daniel, J. S., Kainuma, M. L. T., Lamarque, J. F., ... Thomson, A. G. J. M. V. (2011). The RCP greenhouse gas concentrations and their extensions from 1765 to 2300. Climatic Change, 109, 213-241.

Mitchell, T. D., Carter, T. R., Jones, P. D., Hulme, M., \& New, M. (2004). A comprehensive set of high-resolution grids of monthly climate for Europe and the globe: The observed record (1901-2000) and 16 scenarios (2001-2100). Tyndall Centre for Climate Change Research Working Paper, 55, 25.

Moyano, F. E., Vasilyeva, N. A., Bouckaert, L., Cook, F., Craine, J. M., Don, A., ... Katterer, T. (2012). The moisture response of soil heterotrophic respiration: Interaction with soil properties. Biogeosciences, 9, 1173-1182.

Nishina, K., Ito, A., Beerling, D. J., Cadule, P., Ciais, P., Clark, D. B., ... Keribin, R. (2014). Quantifying uncertainties in soil carbon responses to changes in global mean temperature and precipitation. Earth System Dynamics, 5, 197209. https://doi.org/10.5194/esd-5-197-2014

Parton, W., Schimel, D. S., Cole, C., \& Ojima, D. (1987). Analysis of factors controlling soil organic matter levels in Great Plains grasslands. Soil Science 
Society of America journal (USA), 51, 1173-1179. https://d oi.org/10.2136/sssaj1987.03615995005100050015x

Perveen, N., Barot, S., Alvarez, G., Klumpp, K., Martin, R., Rapaport, A., \& Fontaine, S. (2014). Priming effect and microbial diversity in ecosystem functioning and response to global change: A modeling approach using the SYMPHONY model. Global Change Biology, 20, 1174-1190.

Raich, J., \& Schlesinger, W. (1992). The global carbon dioxide flux in soil respiration and its relationship to vegetation and climate. Tellus Series B, 44, 81-99. https://doi.org/10.3402/tellusb.v44i2.15428

Richey, J. E., Melack, J. M., Aufdenkampe, A. K., Ballester, V. M., \& Hess, L. L. (2002). Outgassing from Amazonian rivers and wetlands as a large tropical source of atmospheric $\mathrm{CO}_{2}$. Nature, 416, 617-620.

https://doi.org/10.1038/416617a

Santaren, D., Peylin, P., Viovy, N., \& Ciais, P. (2007). Optimizing a processbased ecosystem model with eddy-covariance flux measurements: A pine forest in southern France. Global Biogeochemical Cycles, 21, GB2013.

Scharlemann, J. P., Tanner, E. V., Hiederer, R., \& Kapos, V. (2014). Global soil carbon: Understanding and managing the largest terrestrial carbon pool. Carbon Management, 5, 81-91. https://doi.org/10.4155/ cmt.13.77

Sulman, B. N., Phillips, R. P., Oishi, A. C., Shevliakova, E., \& Pacala, S. W. (2014). Microbe-driven turnover offsets mineral-mediated storage of soil carbon under elevated $\mathrm{CO}_{2}$. Nature Climate Change, 4, 1099- 1102.

https://doi.org/10.1038/nclimate2436

Tang, J., \& Riley, W. J. (2014). Weaker soil carbon-climate feedbacks resulting from microbial and abiotic interactions. Nature Climate Change, 5, 56-60.

Tarantola, A. (1987). Inverse problem theory: methods for data fitting and model parameter estimation (ed Elsevier). 644 pp.

Taylor, K. E., Stouffer, R. J., \& Meehl, G. A. (2012). An overview of CMIP5 and the experiment design. Bulletin of the American Meteorological Society, 93, 485-498. https://doi.org/10.1175/BAMS-D-11- 00094.1

Todd-Brown, K. E. O., Randerson, J. T., Post, W. M., Hoffman, F. M., Tarnocai, C., Schuur, E. a. G., \& Allison, S. D. (2013). Causes of variation in soil carbon simulations from CMIP5 Earth system models and comparison with observations. Biogeosciences, 10, 1717-1736. https://d oi.org/10.5194/bg10-1717-2013 
Velicer, G. J., \& Lenski, R. E. (1999). Evolutionary trade-offs under conditions of resource abundance and scarcity: Experiments with bacteria. Ecology, 80, 1168. https://doi.org/10.1890/0012-9658(1999)080 [1168:ETOUCO]2.0.CO;2

Warszawski, L., Frieler, K., Huber, V., Piontek, F., Serdeczny, O., \& Schewe, J. (2014). The Inter-Sectoral Impact Model Intercomparison Project (ISI-MIP):

Project framework. Proceedings of the National Academy of Sciences of the United States of America, 111, 3228-3232.

https://doi.org/10.1073/pnas.1312330110

Wieder, W. R., Allison, S. D., Davidson, E. A., Georgiou, K., Hararuk, O., He, Y., ... Todd-Brown, K. (2015). Explicitly representing soil microbial processes in Earth system models. Global Biogeochemical Cycles, 29, 1782-1800. https://doi.org/10.1002/2015GB005188

Wieder, W. R., Boehnert, J., Bonan, G. B., \& Langseth, M. (2014). Regridded Harmonized World Soil Database v1.2. Wieder, W. R., Bonan, G. B., \& Allison, S. D. (2013). Global soil carbon projections are improved by modelling microbial processes. Nature Climate Change, 3, 1-4.

Wutzler, T., \& Reichstein, M. (2008). Colimitation of decomposition by substrate and decomposers- a comparison of model formulations. Biogeosciences, 5, 749-759. https://doi.org/10.5194/bg-5-749-2008

Xiao, C., Guenet, B., Zhou, Y., Su, J., \& Janssens, I. A. (2015). Priming of soil organic matter decomposition scales linearly with microbial biomass response to litter input in steppe vegetation. Oikos, 124, 649-657. 